\title{
Tolerância de genótipos de soja à ferrugem-asiática
}

\author{
Tolerance of soybean genotypes to Asian rust
}

\section{Carlos Lásaro Pereira de Melo ${ }^{\mathrm{I}}$ Alexandre Dinnys Roese ${ }^{\mathrm{II}}$ Augusto César Pereira Goulart ${ }^{\mathrm{II}}$}

RESUMO

O objetivo deste estudo foi avaliar o comportamento de diferentes genótipos de soja quanto à tolerância à ferrugemasiática-da-soja (FAS), em condições de campo. Foram conduzidos experimentos, em dois anos consecutivos, no delineamento experimental de blocos ao acaso, com quatro repetições, em esquema fatorial, com oito níveis para genótipos de soja e três para aplicação de fungicida na parte aérea das plantas. Verificouse suficiente variabilidade entre os genótipos avaliados quanto à tolerância à FAS, com alta interação com o ano. Os genótipos mais precoces apresentaram reduções de produtividade inferiores aos de ciclo mais tardio. A cultivar 'BRS 239' foi caracterizada como tolerante à FAS, pelo fato de as produtividades com e sem controle da doença não apresentarem diferenças significativas. A cultivar 'BRSGO 7560', apesar de apresentar ciclo mais tardio, comportou-se como tolerante à FAS, sem redução significativa da produtividade em condições de estresse pelo patógeno, na ausência de controle da doença, o que garantiu maior estabilidade produtiva.

Palavras-chave: Phakopsora pachyrhizi, estabilidade produtiva, produtividade de grãos, Glycine max.

\section{ABSTRACT}

The aim of this study was to evaluate the behavior of different soybean genotypes for tolerance to Asian Soybean Rust (ASR) in field conditions. Experiments were carried out in two consecutive years in a randomized block design with four replications in a factorial arrangement with eight levels for soybean genotypes and three for fungicide application in the leaves. There was sufficient variability among genotypes for tolerance to ASR, with high interaction with year. In general, the earlier genotypes showed lower reductions in productivity than the later cycle genotypes. The cultivar 'BRS 239'was characterized as tolerant to ASR, because the yields with and without disease control was not significant. Cultivar 'BRSGO 7560', despite a later cycle, behaved like tolerant to ASR without significant yield reduction under stress by the pathogen in the absence of disease control, which earned greater yield stability.

Key words: Phakopsora pachyrhizi, yield stability, grain yield, Glycine max.

\section{INTRODUÇÃO}

As doenças têm se destacado como um dos principais fatores de redução da produtividade de soja, contribuindo com o aumento dos custos de produção e sendo responsáveis por reduções anuais de produção de cerca de $15 \%$ a $20 \%$ (TECNOLOGIAS..., 2010). Dentre as doenças que afetam a cultura, destacase a ferrugem-asiática-da-soja - FAS (Phakopsora pachyrhizi Syd. \& P.Syd.), relatada pela primeira vez no Brasil em 2001. Desde a safra agrícola de 2003/2004, essa doença tem sido constatada em todas as regiões produtoras de soja no país, exceto em Roraima, causando perdas da ordem de $10 \%$ a $90 \%$ (YORINORI et al., 2005).

A adoção de manejo integrado da FAS, utilizando diferentes táticas de controle, torna-se necessária para atender ao propósito de eficiência e sustentabilidade no controle de doenças. Em soja, o controle das doenças por meio de cultivares resistentes tem sido efetivo e duradouro para várias doenças importantes, tais como a mancha olho-de-rã (Cercospora sojina) e o cancro-da-haste (Diaporthe phaseolorum f. sp. meridionalis). Todavia, o desenvolvimento de genótipos resistentes à FAS,

\footnotetext{
${ }^{I}$ Centro Nacional de Pesquisa de Soja, Empresa Brasileira de Pesquisa Agropecuária (Embrapa Soja), 70770-901, Londrina, PR, Brasil. E-mail: carlos.lasaro@embrapa.br. Autor para correspondência.

${ }^{\mathrm{II}}$ Centro de Pesquisa Agropecuária Oeste, Embrapa Agropecuária Oeste, Dourados, MS, Brasil. 
portadores de genes maiores, ou ainda resistências ditas verticais, tem sido um grande desafio para a pesquisa (CALVO et al., 2008; PIEROZZI et al., 2008; MAPHOSA et al., 2013).

Trabalhos têm mostrado a existência de variação do germoplasma de soja brasileiro quanto à resistência horizontal ao fungo $\boldsymbol{P}$. pachyrhizi (JULIATTI et al., 2004; OLIVEIRA et al., 2005). Entretanto, a quantificação desse modo de resistência é mais difícil, limitando o seu uso (HARTMAN et al., 2005). Devido à instabilidade da resistência vertical e às dificuldades associadas com a identificação e quantificação da resistência horizontal, outros métodos têm sido utilizados como estratégia de melhoramento, para evitar reduções de produtividade com a incidência da FAS, dentre eles o estudo da tolerância. A tolerância de plantas a doenças é resultante de características quantitativas, específicas e herdáveis da planta, as quais, embora possibilitem que o patógeno infecte, colonize e multiplique-se no hospedeiro, faz com que a planta suporte a doença sem perdas severas em produtividade ou qualidade, similar ao hospedeiro sadio (AGRIOS, 2005).

A estabilidade produtiva (tolerância), caracterizada pela seleção de genótipos de soja com alto potencial produtivo e reduzida queda de produtividade em condições de estresse pela FAS, tem sido uma estratégia importante no manejo integrado dessa doença (KAWUKI et al., 2004; HARTMAN et al., 2005; OLIVEIRA et al., 2005). Um genótipo tolerante apresenta sintomas semelhantes àqueles de um genótipo suscetível, porém é menos danificado pela infecção. Reduções em produtividade normalmente são utilizadas para avaliar o nível de tolerância e, assim, quanto menor a redução, maior o nível de tolerância. Dessa forma, cultivares mais tolerantes podem demandar menor número de aplicações de fungicidas e, assim, contribuir com a redução nos custos de produção da lavoura.

O objetivo deste estudo foi avaliar o comportamento de diferentes genótipos de soja quanto à tolerância à FAS.

\section{MATERIAL E MÉTODOS}

Os experimentos foram instalados no campo experimental da Embrapa Agropecuária Oeste, em Dourados, MS, com as seguintes coordenadas geográficas: latitude de $22^{\circ} 16^{\prime} 30^{\prime}$ ' S, longitude de 54 49' $00^{\circ}$ " W e $408 \mathrm{~m}$ de altitude. $\mathrm{O}$ delineamento experimental utilizado foi o de blocos completos casualizados, em esquema fatorial $8 \times 3$, com quatro repetições, sendo cada parcela constituída de quatro fileiras, espaçadas de $0,50 \mathrm{~m}$, com $6 \mathrm{~m}$ de comprimento cada.
Foram avaliadas sete cultivares comerciais e uma linhagem avançada de soja, em um esquema de aplicação de fungicida na parte aérea das plantas, da seguinte forma: (i) sem aplicação de fungicida; (ii) uma aplicação realizada no surgimento dos primeiros sintomas; e iii) duas aplicações, sendo a primeira no surgimento dos primeiros sintomas e a última aos 15 dias após a primeira aplicação. As aplicações foram efetuadas com pulverizador costal pressurizado com $\mathrm{CO}_{2}$, com vazão de $200 \mathrm{~L} \mathrm{ha}^{-1}$ e bico leque. Foi utilizado o fungicida azoxistrobina + ciproconazole $(60+24$ gramas de ingrediente ativo por hectare, respectivamente), na dosagem de $0,3 \mathrm{~L} \mathrm{ha} \mathrm{ha}^{-1}$ do produto comercial. Também se acrescentou óleo mineral parafínico (Nimbus), na proporção de $0,5 \%$ do volume de calda, seguindo as recomendações do fabricante. Os genótipos testados e seus respectivos Grupos de Maturidade Relativa (GMR) foram: 'BRS 291RR' (6.6), 'NK 7059RR' (6.2), 'BRS 245RR' (7.5), 'BRS Favorita RR' (7.9), 'BRS 239' (6.9), 'BRS 320' (6.2), 'BR 02-04844' (7.2) e 'BRSGO 7560' (7.4). Destes, apenas a cultivar 'NK 7059RR' e a linhagem 'BR 02-04844' apresentam tipo de crescimento indeterminado, e a cultivar 'BRSGO 7560' é a única que possui gene de resistência monogênica, a qual é oriunda da fonte 'BR01-18437' (PIEROZZI et al., 2008).

Os experimentos foram conduzidos em duas safras consecutivas, com semeaduras em $08 / 12 / 2009$ e $04 / 12 / 2010$. As semeaduras foram efetuadas tardiamente, como estratégia de aumentar a pressão de inóculo e para surgimento da doença ainda na fase vegetativa; a quantidade de sementes por metro linear foi padronizada para uma população final de 300 mil plantas ha-1. A adubação de base, inoculação com estirpes de Bradyrhizobium sp., e o manejo cultural da soja, durante toda a condução dos experimentos, foram realizados conforme recomendações técnicas (TECNOLOGIAS..., 2010). As avaliações foram feitas nas duas fileiras centrais, eliminando-se $0,5 \mathrm{~m}$ das extremidades, devido ao efeito de bordadura, constituindo-se em uma área útil de $5 \mathrm{~m}^{2}$. Foram avaliados os graus médios de severidade, em porcentagem (SEV), com auxílio da escala diagramática elaborada por GODOY et al. (2006). Cada dado de severidade foi obtido pela avaliação de 30 folíolos por parcela, igualmente distribuídos entre os terços inferior, médio e superior das plantas e coletados de forma distribuída na área útil da parcela, em duas avaliações: a primeira aos 20 dias após a primeira aplicação do fungicida e a segunda, sete dias após a segunda aplicação, em todos os tratamentos. Foram avaliadas também a produtividade 
média de grãos (REND), em $\mathrm{kg} \mathrm{ha}^{-1}$, padronizada para $13 \%$ de umidade; o ciclo total médio dos genótipos, em dias, da emergência ao estádio $R_{8}(D M)$ e o peso médio de 100 sementes, em gramas (P100).

Para avaliar a tolerância, os danos foram calculados pela diferença entre o valor médio dos tratamentos com aplicações de fungicida (controlados) e o tratamento sem aplicação (não controlado) para as variáveis REND e P100, em cada genótipo testado, semelhante ao estudado por outros autores (OLIVEIRA et al., 2005; CARNEIRO, 2007; KOGA, 2008). Os dados foram submetidos à análise de variância e as médias dos tratamentos comparadas pelo teste de Tukey $(\mathrm{P}<0,05)$, com auxílio do programa estatístico SAS, versão 9.3.

\section{RESULTADOS E DISCUSSÃO}

Foram observados efeitos significativos $(\mathrm{P}<0,05)$ dos fatores ano, genótipo, tratamento com fungicida e da interação de ano com genótipo para todos os caracteres avaliados. Por outro lado, as interações genótipos $\mathrm{x}$ tratamento com fungicida, ano $\mathrm{x}$ tratamento com fungicida e a interação tripla não apresentaram efeitos significativos $(\mathrm{P}>0,05)$ para as variáveis em estudo. SILVA et al. (2007), ao avaliarem quatro genótipos de soja e três fungicidas - incluindo o mesmo empregado neste estudo, observaram interação entre estes fatores no controle da FAS. No entanto, o mesmo resultado não foi observado neste trabalho ao avaliarmos a possível interação entre genótipo e número de aplicações do mesmo fungicida.

A maioria das variáveis apresentaram coeficientes de variação experimental (CVe) abaixo de 20\% (Tabela 1), exceto para a variável SEV, indicando boa precisão experimental. RESENDE \& DUARTE (2007) propuseram um novo parâmetro em detrimento ao CVe, a acurácia seletiva (AS), que avalia a qualidade do experimento em uma abordagem genética e estatística, e não somente sob a perspectiva estatística. Esse parâmetro corresponde à correlação entre o valor genotípico verdadeiro do tratamento genético e aquele estimado a partir das informações experimentais. Nesse contexto, a AS para todas as variáveis em estudo neste trabalho foram classificadas como muito altas, ou seja, acima de 0,90 (Tabela 1).

A produtividade média dos dois anos foi de $1.806,08 \mathrm{~kg} \mathrm{ha}^{-1}$, abaixo da média de produtividade do Estado de Mato Grosso do Sul nas safras 2009/2010 e 2010/2011, que foram de $3.100 \mathrm{~kg} \mathrm{ha}^{-1}$ e $2.937 \mathrm{~kg} \mathrm{ha}^{-1}$, respectivamente (CONAB, 2013). Esse resultado era esperado por dois motivos: primeiro, os experimentos, em ambas as safras, foram semeados tardiamente, já no final da época indicada para semeadura da cultura na região, sendo uma época em que as cultivares têm apresentado os menores potenciais produtivos, comparado à época preferencial, que normalmente ocorre no mês de novembro, para a região de Dourados (FIETZ \& RANGEL, 2008); segundo, a presença de tratamentos sem controle da FAS, nos quais a produtividade média foi muito prejudicada, ocasionando uma redução na média geral.

Quando se analisa a diferença entre os anos, a safra 2010/2011 obteve a maior média de produtividade com $1.841,15 \mathrm{~kg} \mathrm{ha}{ }^{-1}$. Este resultado era esperado, de acordo com as condições climáticas apresentadas na figura 1. Observou-se que a variação da temperatura do ar foi mínima, durante a condução dos experimentos, entre as safras 2009/10 e 2010/2011, enquanto que, para precipitação e umidade relativa do ar, ocorreram variações mais acentuadas. Na safra 2009/2010, houve uma precipitação menor do que na safra 2010/2011, entre os meses de fevereiro e março, coincidindo com as fases mais sensíveis a estresses pelas plantas. Aliado a esse fator, a umidade relativa do ar foi maior neste mesmo período de precipitação, na safra 2010/2011 (Figura 1). Desse modo, ao analisar os dois fatores concomitantemente, a safra 2010/2011, apesar de ter sido mais favorável ao patógeno, resultando em maior severidade da FAS, também proporcionou melhores condições climáticas para o crescimento e desenvolvimento adequados das plantas, garantindo maiores médias de REND, DM e P100 (Tabela 1).

A maior produtividade na safra 2010/2011, em uma situação de maior severidade, foi devido às condições climáticas mais favoráveis ao desenvolvimento das plantas. Este fato pode ser explicado também pela entrada da FAS ter ocorrido tardiamente, quando a maioria dos genótipos encontrava-se entre os estádios $\mathrm{R}_{3}$ e $\mathrm{R}_{5}$ (início de formação de vagens e início de enchimento de grãos, respectivamente). A produtividade (REND) na safra 2009/2010 foi maior para as cultivares 'NK 7059RR', 'BRS 320' e 'BRSGO 7560'. Contrariamente, a cultivar 'BRS Favorita RR' apresentou a menor média produtiva, não diferindo das médias das cultivares 'BRS 291RR' e 'BRS 245RR' (Tabela 1). Já na safra 2010/2011, a cultivar 'BRS 320' obteve a maior média de produtividade de grãos, e a 'NK 7059RR' apresentou uma das menores produtividades, caracterizando a interação de genótipos por ambiente, ou seja, os genótipos expressaram diferencialmente seu potencial produtivo entre os diferentes anos.

O maior ciclo (DM) dos genótipos de soja na safra 2010/2011 implicou maior tempo de exposição das plantas à infecção pela FAS. Além 
Tabela 1 - Produtividade média de grãos em $\mathrm{kg} \mathrm{ha}^{-1}$ (REND), ciclo total médio (DM), em dias, peso médio de 100 sementes (P100), em gramas, e severidade média da ferrugem (SEV), em porcentagem, na avaliação de diferentes genótipos de soja, em duas safras agrícolas. Dourados, MS.

\begin{tabular}{|c|c|c|c|c|}
\hline Genótipos & $2009 / 2010$ & $2010 / 2011$ & $2009 / 2010$ & $2010 / 2011$ \\
\hline 'BRS 291RR' & $1.346,24 \mathrm{c}$ & $1.831,24 \mathrm{bc}$ & $97,00 \mathrm{~d}$ & $109,30 \mathrm{bc}$ \\
\hline 'NK 7059RR' & $2.189,07 \mathrm{a}$ & $1.567,29 \mathrm{c}$ & $98,00 \mathrm{~cd}$ & $106,25 \mathrm{c}$ \\
\hline 'BRS 245RR' & $1.417,57 \mathrm{c}$ & $2.098,51 \mathrm{ab}$ & $99,33 \mathrm{~b}$ & $112,87 \mathrm{ab}$ \\
\hline 'BRS Favorita RR' & $1.237,91 \mathrm{c}$ & $951,03 \mathrm{~d}$ & $102,44 \mathrm{a}$ & $117,19 \mathrm{a}$ \\
\hline 'BRS 239' & $1.867,52 \mathrm{~b}$ & $2.254,45 \mathrm{ab}$ & $97,22 \mathrm{~d}$ & $104,33 \mathrm{c}$ \\
\hline 'BRS 320' & $2.029,29 \mathrm{ab}$ & $2.523,48 \mathrm{a}$ & $94,66 \mathrm{e}$ & $94,41 \mathrm{~d}$ \\
\hline 'BR02-04844' & $1.821,97 \mathrm{~b}$ & $1.541,59 \mathrm{c}$ & $98,77 \mathrm{bc}$ & $112,27 \mathrm{ab}$ \\
\hline 'BRSGO 7560' & $2.037,60 \mathrm{ab}$ & $1.961,64 \mathrm{bc}$ & $97,55 \mathrm{~cd}$ & $104,95 \mathrm{c}$ \\
\hline Médias & $1.743,40 \mathrm{~B}$ & $1.841,15 \mathrm{~A}$ & $98,12 \mathrm{~B}$ & $107,70 \mathrm{~A}$ \\
\hline $\mathrm{CVe}(\%)^{\#}$ & 10,83 & 18,15 & 1,00 & 3,90 \\
\hline $\mathrm{AS}^{\# \#}$ & 0,99 & 0,97 & 0,99 & 0,98 \\
\hline Genótipos & $2009 / 2010$ & $2010 / 2011$ & $2009 / 2010$ & $2010 / 2011$ \\
\hline 'BRS 291RR' & $9,69 \mathrm{~b}$ & $10,33 \mathrm{ab}$ & $7,13 \mathrm{abc}$ & $34,16 \mathrm{ab}$ \\
\hline 'NK 7059RR' & $12,12 \mathrm{a}$ & $10,42 \mathrm{ab}$ & $7,75 \mathrm{ab}$ & $22,10 \mathrm{c}$ \\
\hline 'BRS 245RR' & $8,16 \mathrm{c}$ & $9,61 \mathrm{~b}$ & $4,04 \mathrm{c}$ & $26,32 \mathrm{bc}$ \\
\hline 'BRS Favorita RR' & $8,73 \mathrm{c}$ & $8,19 \mathrm{c}$ & $4,51 \mathrm{c}$ & $19,81 \mathrm{c}$ \\
\hline 'BRS 239' & $10,06 \mathrm{~b}$ & $11,08 \mathrm{a}$ & $4,34 \mathrm{c}$ & $30,56 \mathrm{abc}$ \\
\hline 'BRS 320' & $10,16 b$ & $11,17 \mathrm{a}$ & $5,40 \mathrm{bc}$ & $39,88 \mathrm{a}$ \\
\hline 'BR02-04844' & $8,49 \mathrm{c}$ & $9,60 \mathrm{~b}$ & $5,93 \mathrm{abc}$ & $25,49 \mathrm{bc}$ \\
\hline 'BRSGO 7560' & $12,04 \mathrm{a}$ & $11,42 \mathrm{a}$ & $8,61 \mathrm{a}$ & $27,89 \mathrm{bc}$ \\
\hline Médias & 9,93 В & $10,23 \mathrm{~A}$ & $5,96 \mathrm{~B}$ & $28,28 \mathrm{~A}$ \\
\hline $\mathrm{CVe}(\%)^{\#}$ & 4,84 & 10,67 & 41,69 & 32,08 \\
\hline $\mathrm{AS}^{\# \#}$ & 1,00 & 0,94 & 0,91 & 0,92 \\
\hline
\end{tabular}

${ }^{*}$ Médias seguidas por letras distintas, minúsculas na coluna e maiúsculas na linha, diferem entre si pelo teste de Tukey $(\mathrm{P}<0,05)$. ${ }^{*} \mathrm{CVe}(\%)$ Coeficiente de Variação experimental. ${ }^{\#}$ AS - Acurácia Seletiva.

disso, o maior número de dias com chuva superior a $1,0 \mathrm{~mm}$ nesta safra (17 dias a mais) contribuiu para uma maior média de severidade, comparado à safra 2009/2010. Na safra 2009/2010, a cultivar 'BRS 245RR' apresentou a menor média de SEV, diferindo somente das cultivares 'NK 7059RR' e 'BRSGO 7560'. Já na safra 2010/2011, a cultivar 'BRS Favorita RR' obteve a menor média de SEV, diferindo somente das cultivares 'BRS 291RR' e 'BRS 320' (Tabela 1). A correlação entre as variáveis REND e SEV foi de $0,52(\mathrm{P}>0,05)$, indicando uma certa associação entre as características, porém não significativa.

As cultivares 'NK 7059RR' e 'BRSGO 7560' apresentaram as maiores médias de P100 na safra 2009/2010. Por outro lado, a cultivar 'BRS 245RR' apresentou a menor média de P100, não diferindo das médias da cultivar 'BRS Favorita RR' e da linhagem 'BR02-04844' (Tabela 1). Na safra 2010/2011, as cultivares 'BRSGO 7560', 'BRS 320', 'BRS 239', 'NK 7059RR' e 'BRS 291RR' obtiveram as maiores médias de P100.

$\mathrm{O}$ uso de genótipos precoces tem sido uma das estratégias recomendadas para evitar danos significativos à produtividade, pela incidência da FAS (KAWUKI et al., 2004; HARTMAN et al., 2005). No manejo de escape com o uso de cultivares de ciclo precoce, caracterizado pelo princípio da evasão, a cultura fica menos tempo no campo, reduzindo os danos causados pelo fungo (SILVA et al., 2007).

Neste trabalho, verificou-se que houve uma tendência dos genótipos mais precoces apresentarem as menores reduções de produtividade, inferiores 


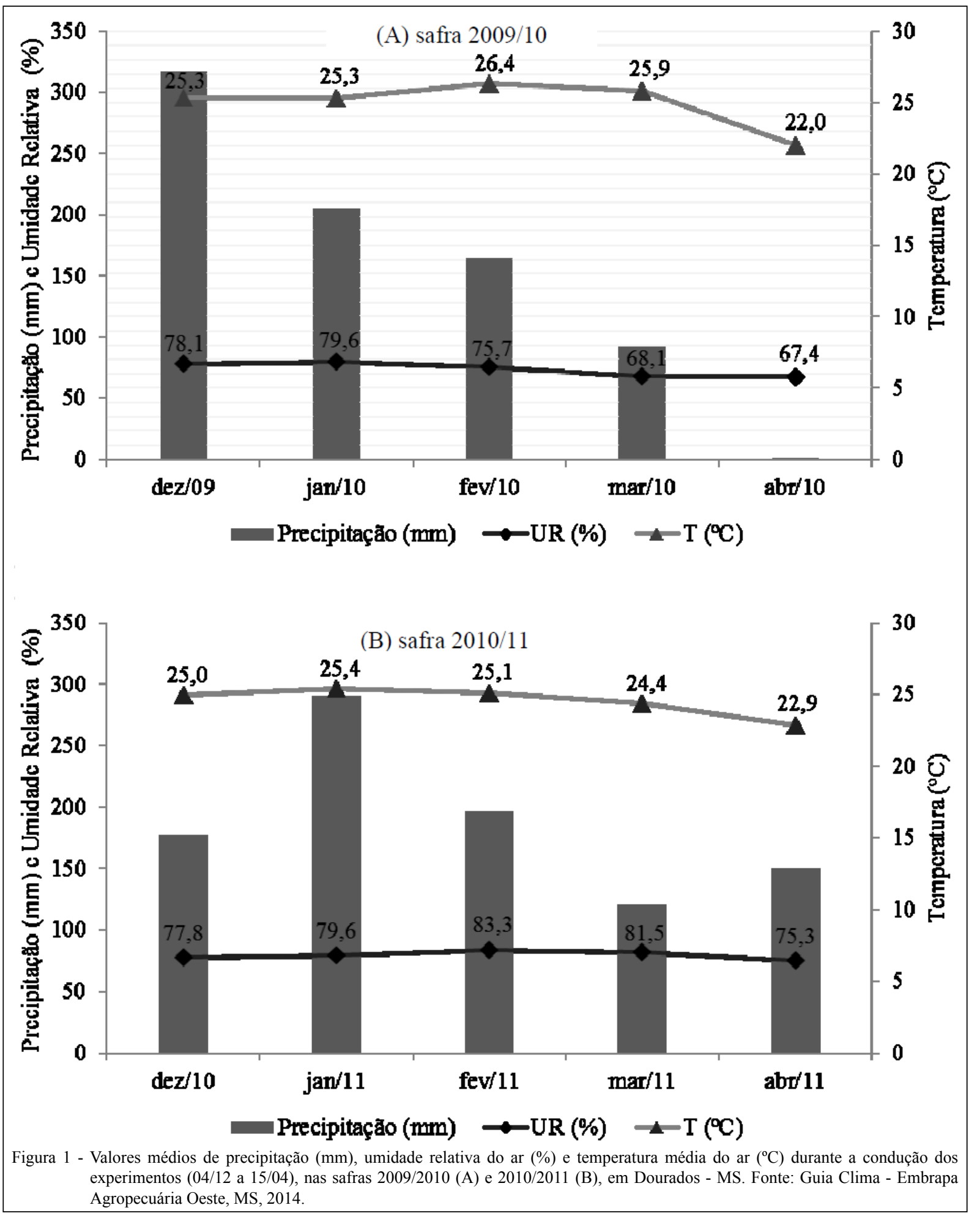

aos genótipos de ciclos semiprecoce a médios (Tabelas 1 e 2), com exceção da cultivar 'BRSGO 7560'. Este resultado foi semelhante aos obtidos por outros autores (OLIVEIRA et al., 2005; CARNEIRO, 2007; KOGA, 2008), os quais relataram que as reduções na produtividade foram superiores nos genótipos de ciclo tardio, em relação às cultivares de ciclo médio, semiprecoce ou precoce. Dessa forma, este estudo corrobora a afirmação de que os genótipos de ciclo mais prolongado geralmente sofrem maiores 
Tabela 2 - Produtividade média de grãos (REND) e peso de 100 sementes (P100) de oito genótipos de soja com e sem aplicação de fungicida, e suas respectivas reduções e porcentagem das reduções observadas em condições de campo, na média das safras agrícolas $2009 / 10$ e $2010 / 11$.

\begin{tabular}{|c|c|c|c|c|c|c|c|}
\hline \multirow{2}{*}{ Genótipos } & \multirow{2}{*}{ FUNGICIDA } & \multirow{2}{*}{ REND (kg ha-1) } & \multirow{2}{*}{$\mathrm{P} 100(\mathrm{~g})$} & \multicolumn{2}{|c|}{---- Reduções --.-- } & \multicolumn{2}{|c|}{--- \% reduções --.- } \\
\hline & & & & REND & P100 & REND & P100 \\
\hline \multirow{3}{*}{ 'BRS 291RR' } & sem aplicação & $1.312,35$ & 8,95 & \multirow{4}{*}{$414,58^{* *}$} & \multirow{4}{*}{$1,58^{* *}$} & \multirow{4}{*}{24,01} & \multirow{4}{*}{15,00} \\
\hline & 1 aplicação & $1.649,01$ & 10,09 & & & & \\
\hline & 2 aplicações & $1.804,84$ & 10,97 & & & & \\
\hline Média aplicações & 1 e 2 aplicações & $1.726,93$ & 10,53 & & & & \\
\hline \multirow{3}{*}{ 'NK 7059RR' } & sem aplicação & $1.684,11$ & 10,12 & \multirow{4}{*}{$291,11^{* *}$} & \multirow{4}{*}{$1,72^{* *}$} & \multirow{4}{*}{14,74} & \multirow{4}{*}{14,53} \\
\hline & 1 aplicação & $1.790,63$ & 11,65 & & & & \\
\hline & 2 aplicações & $2.159,8$ & 12,02 & & & & \\
\hline Média aplicações & 1 e 2 aplicações & $1.975,22$ & 11,84 & & & & \\
\hline \multirow{3}{*}{ 'BRS 245RR' } & sem aplicação & $1.382,28$ & 8,58 & \multirow{4}{*}{$563,64^{* *}$} & \multirow{4}{*}{$0,46^{\mathrm{ns}}$} & \multirow{4}{*}{28,97} & \multirow{4}{*}{5,09} \\
\hline & 1 aplicação & $1.898,03$ & 8,58 & & & & \\
\hline & 2 aplicações & $1.993,81$ & 9,49 & & & & \\
\hline Média aplicações & 1 e 2 aplicações & $1.945,92$ & 9,04 & & & & \\
\hline \multirow{3}{*}{ 'BRS Favorita RR' } & sem aplicação & $1.003,45$ & 7,80 & \multirow{4}{*}{$285,99^{* *}$} & \multirow{4}{*}{$0,98^{* *}$} & \multirow{4}{*}{22,18} & \multirow{4}{*}{11,16} \\
\hline & 1 aplicação & $1.243,28$ & 8,95 & & & & \\
\hline & 2 aplicações & $1.335,62$ & 8,61 & & & & \\
\hline Média aplicações & 1 e 2 aplicações & $1.289,44$ & 8,78 & & & & \\
\hline \multirow{3}{*}{ 'BRS 239' } & sem aplicação & $1.909,23$ & 9,97 & \multirow{4}{*}{$227,64^{\mathrm{ns}}$} & & & \\
\hline & 1 aplicação & $2.207,47$ & 10,61 & & & & \\
\hline & 2 aplicações & $2.066,26$ & 11,12 & & $0,90^{* *}$ & 10,65 & 8,28 \\
\hline Média aplicações & 1 e 2 aplicações & $2.136,87$ & 10,87 & & & & \\
\hline & sem aplicação & $2.032,67$ & 9,98 & & & & \\
\hline 'BRS 320' & 1 aplicação & $2.439,76$ & 11,12 & & & & \\
\hline & 2 aplicações & $2.356,71$ & 10,88 & $365,57^{*}$ & $1,02^{* *}$ & 15,24 & 9,27 \\
\hline Média aplicações & 1 e 2 aplicações & $2.398,24$ & 11,00 & & & & \\
\hline & sem aplicação & $1.468,84$ & 8,57 & & & & \\
\hline 'BR 02-04844' & 1 aplicação & $1.795,26$ & 9,19 & & & & \\
\hline & 2 aplicações & $1.781,24$ & 9,35 & $319,41^{*}$ & $0,70^{\text {ns }}$ & 17,86 & 7,55 \\
\hline Média aplicações & 1 e 2 aplicações & $1.788,25$ & 9,27 & & & & \\
\hline & sem aplicação & $2.002,42$ & 10,88 & & & & \\
\hline 'BRSGO 7560’ & 1 aplicação & $1.981,07$ & 12,27 & & & & \\
\hline & 2 aplicações & $2.015,37$ & 12,03 & $-4,2^{\text {ns }}$ & $1,27^{* *}$ & 0,00 & 10,45 \\
\hline Média aplicações & 1 e 2 aplicações & $1.998,22$ & 12,15 & & & & \\
\hline
\end{tabular}

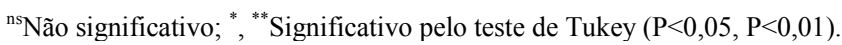


reduções no rendimento, por permanecerem mais tempo expostos à infecção pelo patógeno.

$\mathrm{Na}$ tabela 2, observam-se as reduções ocasionadas pela FAS nas variáveis REND e P100, e suas respectivas porcentagens, mensuradas pela diferença entre os tratamentos sem aplicação de fungicida e aqueles com aplicação, na média dos dois anos. Com exceção das cultivares 'BRSGO 7560' e 'BRS 239', os demais genótipos apresentaram diferença significativa entre a média dos tratamentos com controle e o tratamento sem controle, para a variável REND, evidenciando ausência de tolerância desses genótipos de soja à FAS.

A maior redução de produtividade, ocasionada pela FAS foi obtida na cultivar 'BRS 245RR', seguida pelas cultivares 'BRS 291RR' e 'BRS Favorita RR', indicando alta intolerância destas à FAS (Tabela 2). Observou-se que a 'BRS Favorita RR', mesmo possuindo uma das menores médias de SEV, em ambas as safras, apresentou baixa produtividade; já a 'BRSGO 7560' apresentou uma das mais altas SEV, entretanto, obteve uma das maiores médias de REND.

KAWUKI et al. (2004) avaliaram tolerância de genótipos de soja à FAS e verificaram que genótipos precoces foram mais tolerantes do que os genótipos de ciclo médio e tardio. De maneira semelhante, a não significância da redução em produtividade, detectada na cultivar 'BRS 239', pode ser um indicativo de tolerância à FAS. Esta tolerância pode estar relacionada à reação de resistência aparente ou escape, como destacado por AGRIOS (2005), pelo fato de esta cultivar ter sido uma das mais precoces. Por outro lado, a cultivar 'BRS 320', mesmo possuindo ciclo menor que a 'BRS 239', obteve uma das maiores médias de SEV (Tabela 1), principalmente na safra 2010/2011, e significativa redução no rendimento (Tabela 2), demonstrando que, apesar da precocidade, a 'BRS 320' comportouse como intolerante à FAS. A cultivar 'BRSGO 7560' não apresentou redução de produtividade entre o tratamento sem aplicação e a média dos tratamentos com aplicação de fungicida (Tabela 2). Esse comportamento confirma os resultados discutidos acerca desta cultivar, perante os dados obtidos na tabela 2 , indicando a reação de tolerância à FAS em condições de campo, associada à boa estabilidade produtiva. Neste trabalho, observou-se que a redução em P100 foi significativa para as cultivares 'BRS 239' e 'BRSGO 7560' e não significativa para a cultivar 'BRS 245RR'. OLIVEIRA et al. (2005) também detectaram diferença na queda de P100 em cultivares sem redução expressiva de rendimento. Outrossim, CARNEIRO (2007) verificou que, mesmo em genótipos que a diferença de rendimento não foi significativa, entre subparcelas tratadas e não tratadas, a redução entre peso de mil grãos foi estatisticamente diferente. Ademais, de acordo com os conceitos de tolerância na literatura (AGRIOS, 2005; CARNEIRO, 2007; KAWUKI et al., 2004), as variáveis mais preponderantes na quantificação da tolerância são o rendimento e a intensidade de doença, as quais foram avaliadas neste estudo.

Nesse ínterim, as cultivares 'BRS 239' e 'BRSGO 7560' podem ser boas alternativas de manejo da FAS, dentro de um contexto de manejo integrado vislumbrado pela redução do custo de controle da doença.

\section{CONCLUSÃO}

Genótipos precoces ('BRS 239', 'BRS 320' e 'NK 7059RR') apresentam menores porcentagens de redução de produtividade de grãos, comparados aos genótipos de ciclo mais tardio ('BRS 245RR' e 'BRS Favorita RR'). As cultivares 'BRS 239' e 'BRSGO 7560 ' são tolerantes à FAS. A característica $\mathrm{P} 100$ não é consistente para avaliar a tolerância de genótipos de soja à FAS. Considerando as variáveis REND e SEV, a cultivar 'BRSGO 7560' possui maior estabilidade produtiva, mesmo apresentando ciclo mais longo.

\section{REFERÊNCIAS}

AGRIOS, G.N. Plant pathology. 5.ed. Oxford: Academic, 2005. 922p.

CALVO, E.S. et al. Two major recessive soybean genes conferring soybean rust resistance. Crop Science, v.48, p.1350-1354, 2008. Disponível em: <https://www.crops.org/publications/ cs/pdfs/48/4/1350>. Acesso em: 04 nov. 2013. doi:10.2135/ cropsci2007.10.0589.

CARNEIRO, L.C. Caracterização epidemiológica da resistência parcial e análise de tolerância de genótipos de soja à ferrugem asiática. 2007. 75f. Tese (Doutorado em Agronomia) - Curso de Pós-graduação em Agronomia, Universidade de São Paulo - Escola Superior de Agricultura Luiz de Queiroz, SP.

CONAB. Séries históricas: soja. Brasília, DF, [2013]. Disponível em: $<$ http://www.conab.gov.br/conteudos.php?a=1252\&t=2\&Pagina objcmsconteudos=3\#A_objcmsconteudos $>$. Acesso em: 16 set. 2013 .

FIETZ, C.R.; RANGEL, M.A.S. Época de semeadura da soja para a região de Dourados - MS, com base na deficiência hídrica e no fotoperíodo. Engenharia Agrícola, v.28, p.666-672, 2008. Disponível em: <http://www.scielo.br/pdf/eagri/v28n4/06.pdf > Acesso em: 15 out. 2014. doi: 10.1590/S0100-69162008000400006.

GODOY, C.V. et al. Diagrammatic scale for assessment of soybean rust severity. Fitopatologia Brasileira, v.31, p.63-68, 2006. Disponível em: $<$ http://www.scielo.br/scielo.php?pid=S0100$41582006000100011 \&$ script $=$ sci_arttext $>$. Acesso em: 18 set. 2013. doi: $10.1590 /$ S0100-41582006000100011 
HARTMAN, G.L. et al. Breeding for resistance to soybean rust. Plant Disease, v.89, p.664-666, 2005. Disponível em: <http:// apsjournals.apsnet.org/doi/abs/10.1094/PD-89-0664>. Acesso em: 18 set. 2013. doi: 10.1094/PD-89-0664.

JULIATTI, F.C. et al. Manejo integrado das doenças da soja com ênfase na ferrugem-asiática em plantio direto. In: ZAMBOLIM, L. et al. (Ed.). Manejo integrado: integração agricultura-pecuária. Viçosa, MG: Universidade Federal de Viçosa, 2004. p.73-115.

KAWUKI, R.S. et al. Soybean rust severity, rate of rust development and tolerance as influenced by maturity period and season. Crop Protection, v.23, p.447-455, 2004.

KOGA, L.J. Ferrugem asiática da soja: resistência, controle químico e tolerância. 2008. 92f. Tese (Doutorado em Agronomia) - Curso de Pós-graduação em Agronomia, Universidade Estadual de Londrina, PR.

MAPHOSA, M. et al. Assessment of comparative virulence and resistance in soybean using field isolates of soybean rust. Journal of Agricultural Science, v.5, p.249-257, 2013. Disponível em: $<$ http:// www.ccsenet.org/journal/index.php/jas/article/view/24624/16246>. Acesso em: 04 de nov. 2013. doi: 10.5539/jas.v5n5p249.

OLIVEIRA, A.C.B. et al. Avaliação da tolerância de cultivares de soja à ferrugem-asiática no Oeste da Bahia. Pesquisa Agropecuária Brasileira, v.30, p.658-662, 2005. Disponível em: $<$ http://www.scielo.br/scielo.php?pid=S01004158200500060001 $6 \&$ script $=$ sci_arttext $>$. Acesso em: 18 set. 2013. doi: 10.1590/ S0100-41582005000600016.
PIEROZZI, P.H.B. et al. New soybean (Glycine max Fabales, Fabaceae) sources of qualitative genetic resistance to Asian soybean rust caused by Phakopsora pachyrhizi (Uredinales, Phakopsoraceae). Genetics and Molecular Biology, v.31, p.505-511, 2008. Disponível em: <http://www.scielo.br/scielo. php? pid $=$ S1415-47572008000300018\& script $=$ sci arttext $>$. Acesso em: 18 set. 2013. doi: 10.1590/S1415-47572008000300018.

SILVA, V.A.S. et al. Interação entre resistência genética parcial e fungicidas no controle da ferrugem-asiática da soja. Pesquisa Agropecuária Brasileira, v.42, p.1261-1268, 2007.

RESENDE, M.D.V.; DUARTE, J.B. Precisão e controle de qualidade em experimentos de avaliação de cultivares. Pesquisa Agropecuária Tropical, v.37, n.3, p.182-194, 2007. Disponível em: <http://www.revistas.ufg.br/index.php/pat/article/view/1867>. Acesso em: 01 ago. 2014. doi: 10.5216/pat.v37i3.1867.

TECNOLOGIAS de produção de soja - região Central do Brasil 2011. Londrina: Embrapa Soja; Planaltina, DF: Embrapa Cerrados; Dourados: Embrapa Agropecuária Oeste, 2010. 255p. (Embrapa Soja. Sistemas de produção, n. 14)

YORINORI, J.T. et al. Epidemics of soybean rust (Phakopsora pachyrhizi) in Brazil and Paraguay. Plant Disease, v.89, p.675677, 2005. Disponível em: <http://apsjournals.apsnet.org/doi/ abs/10.1094/PD-89-0675>. Acesso em: 20 ago. 2013. doi: 10.1094/PD-89-0675. 